\title{
Redistribution of alloying elements in Zircaloy-2 after in- reactor exposure
}

\author{
G. Sundell ${ }^{1}$, M. Thuvander1, P. Tejland ${ }^{2}$, M. Dahlbäck ${ }^{3}$, L. Hallstadius ${ }^{3}$, H.-O. Andrén ${ }^{1}$, \\ ${ }^{1}$ Department of Applied Physics, Chalmers University of Technology, SE-412 96 \\ Göteborg, Sweden \\ 2 Studsvik Nuclear AB, SE-611 82 Nyköping, Sweden \\ ${ }^{3}$ Westinghouse Electric Sweden, SE-721 Västerås, Sweden
}

Corresponding author: G. Sundell

gustav.sundell@chalmers.se

Phone: +46-(0)31-772 3291

\section{Abstract}

An atom probe tomography study of the microstructure of a Zircaloy-2 material subjected to 9 annual cycles of BWR exposure has been conducted. Upon dissolution of secondary phase particles, $\mathrm{Fe}$ and $\mathrm{Cr}$ are seen to reprecipitate in large numbers of clusters and particles of 1-5 nm sizes throughout the $\mathrm{Zr}$ metal matrix. Fe and Sn were observed to segregate to ring-shaped features in the metal that are interpreted to be $<\mathrm{c}>$-component vacancy loops. This implies that these two elements play a major role in the irradiation growth phenomenon in $\mathrm{Zr}$ alloys, which is believed to be caused by the formation of $<\mathrm{c}>$-loops. Similarly to autoclave-corroded $\mathrm{Zr}$ alloys, the formation of a sub-oxide layer of approximate composition $\mathrm{ZrO}$ was observed. On the other hand, no oxygen saturated metal phase was detected underneath the oxide scale.

\section{Introduction}

Zirconium alloys have been used as fuel cladding in nuclear reactors for over 50 years due to their combination of desirable properties, in particular a low thermal neutron capture cross-section. Long-term exposure to reactor core environments leads to significant changes in the material properties, arising from the microstructural changes that occur when fast neutrons interact with atoms in the cladding. Each neutron-atom collision may create higher order displacements in cascades affecting more than 200 lattice points [1]. Vacancies and self-interstitials that are generated in the cascades coalesce into <a>-type loops, and upon prolonged exposure, $<c>$-component vacancy type loops also start to develop. A high density of loops causes significant hardening of the material as dislocation slip is impeded. The nucleation of $<\mathrm{c}>$-component vacancy loops has also been linked to accelerated growth of the fuel cladding tubes [2]. 
The distribution of alloying elements in the cladding materials is also greatly affected by the fast neutron fluence. Transition metal elements that are added to the Zircaloys and some other zirconium alloys have low solubility in $\alpha$-Zr and form intermetallic precipitates (SPPs). In Zircaloy-2, two principal families of SPPs are present, namely $\mathrm{Zr}(\mathrm{Fe}, \mathrm{Cr})_{2}$ and $\mathrm{Zr}_{2}(\mathrm{Fe}, \mathrm{Ni})$. The $\mathrm{Zr}(\mathrm{Fe}, \mathrm{Cr})_{2}$ type precipitates are known to go from crystalline to amorphous when subjected to irradiation $[3,4]$, which has been attributed to accumulation of irradiationinduced defects destabilizing the crystalline structure [5]. Amorphization is accompanied by gradual dissolution of the precipitates, and towards the end of the fuel rod lifetime the size and number of SPPs have been greatly reduced. The ultimate fate of $\mathrm{Fe}, \mathrm{Cr}$ and $\mathrm{Ni}$ after leaving SPPs has not been fully established, although observations of reprecipitation manifested in various types of secondary precipitates have been made [6]. It has also been shown that Fe can segregate to and stabilize $<\mathrm{c}>$-loops under electron irradiation, although no evidence of this was seen for neutron irradiated samples [7]. High densities of $<c>-$-loops have also been observed in the vicinity of Fe-depleted SPPs in irradiated Zircaloy-4 [8].

In this study, the redistribution of alloying elements in a Zircaloy-2 material subjected to 9 annual cycles of in-reactor exposure is analyzed using atom probe tomography (APT). Development in instrumentation in recent years has brought a surge of interest in APT for Zr alloy applications, prompting several publications on basic metallurgy and autoclave corrosion properties [9-14]. The aim of this study is to elucidate how irradiation affects the distribution of alloying elements in Zircaloy-2. This knowledge may contribute to a greater understanding of some of the critical limiting phenomena for the lifetime of nuclear fuel cladding, such as irradiation growth, breakaway corrosion and accelerated hydrogen pick-up.

\section{Material}

The investigated material in this study was a Zircaloy-2 cladding tube of the Westinghouse designated LK3 ${ }^{\text {TM }}$ type. The nominal composition of the alloy is presented in Table 1.

Table 1: Nominal composition of the investigated material in wt. $\%$ or wppm, with $\mathrm{Zr}$ as balance.

\begin{tabular}{lllllll}
\hline Sn (\%) & Fe (\%) & Cr (\%) & Ni (\%) & Si (ppm) & $\mathbf{O}(\mathbf{p p m})$ & $\mathbf{N}(\mathbf{p p m})$ \\
\hline 1.32 & 0.17 & 0.10 & 0.05 & 70 & 1300 & 50 \\
\hline
\end{tabular}

The heat treatment of $\mathrm{LK}^{\mathrm{TM}}$ is described by the normalized heat treatment parameter $A$, defined as [15]

$$
A=\sum t_{i} \exp \left(-Q / R T_{i}\right)
$$

where $i$ corresponds to the $i$ th heat treatment after $\beta$-quenching at the temperature $T_{i}(\mathrm{~K})$ during the time $t_{i}(\mathrm{~h}), R$ is the gas constant and $Q$ the activation energy ( $63 \mathrm{kcal} / \mathrm{mol}$ or $264 \mathrm{~kJ} / \mathrm{mol}$ ). 
The accumulated heat treatment parameter $\log A$ is -13.9 , giving it an average final SPP diameter prior to reactor operation of approximately $84 \mathrm{~nm}$. LK3 ${ }^{\mathrm{TM}}$ has been in use in BWR reactors for more than 20 years and vast amounts of data exist on its behavior during operation. The basic metallurgy and the autoclave corrosion properties of the material have been extensively characterized with various microscopy techniques and APT in previous studies [12,16,17]. Prior transmission electron microscopy studies have been carried out on the same fuel rod allowing for comparison with the presented results, and extensive characterization data are presented elsewhere [18].

The degree of irradiation is also described in [18], as follows. The average rod burnup was $78.7 \mathrm{MWd} / \mathrm{kgU}$ with a sample fast neutron fluence $(\mathrm{E}>1 \mathrm{MeV})$ of $16.5 \times 10^{25} \mathrm{n} / \mathrm{m}^{2}$. The axial location of the sample was $1218-1308 \mathrm{~mm}$ from the bottom end. At this high fluence, only the largest SPPs remain intact. The SPP number density has decreased from $6.4 \times 10^{19} \mathrm{~m}^{-3}$ in the unirradiated material to $1.0 \times 10^{19} \mathrm{~m}^{-3}$. The average oxide thickness of the sample was $45 \mu \mathrm{m}$ and the rod hydrogen content was approximately $660 \mathrm{wppm}$ (about 6 at.\%). At the time when the material was retrieved from the reactor, an acceleration in the instantaneous hydrogen pick-up and rod growth was observed. The measured total (lifetime average) hydrogen pick-up fraction was 30\%, and the total rod growth was $42 \mathrm{~mm}$.

\section{Experimental procedures}

Samples were prepared by first cutting a $5 \mathrm{~mm}$ segment of the de-fuelled tube, which was subsequently polished in a hot-cell at an angle to the tube surface to produce a section where the metal-oxide interface was clearly visible. APT specimens were fabricated by the established lift-out procedure, using a combined focused ion beam scanning electron microscope workstation [19]. Two lift-outs were performed yielding a total of 10 APT samples. The analyzed regions were located in the $\mathrm{Zr}$ metal in the close vicinity of the metal-oxide interface, at distances of approximately $0.5-3 \mu \mathrm{m}$ from the oxide. It should be noted that as the samples were retrieved from the outermost regions of the metal, the distribution of alloying elements may differ slightly in the tube interior, particularly with regards to hydrogen.

APT analysis was performed using a local electrode atom probe of model Imago LEAP 3000X HR. Field evaporation is initiated with either voltage pulsing with a $20 \%$ pulse fraction at $200 \mathrm{kHz}$, or laser pulsing using a green laser $(\lambda=532 \mathrm{~nm})$ with pulse energy $0.25 \mathrm{~nJ}$ at $200 \mathrm{kHz}$. The temperature of the specimen during the experiments was held at $70 \mathrm{~K}$ and the pressure in the analysis chamber was approximately $10^{-9} \mathrm{~Pa}$. APT data were analyzed using the Cameca IVAS 3.6.6 software.

\section{Results}

From the 10 samples that were produced, a total of 15 APT analyses were obtained where more than 10 million ions were collected in each analysis. Some samples did not fracture during analysis and could be re-sharpened up to five times, yielding vast amounts of data. The results obtained using laser pulsing 
were reproduced in voltage pulsing mode, thus ensuring that no artifacts were induced by the heating during laser pulsing.

Due to the relatively large volumes of data that were obtained, all analyses contained at least one, and in some cases several grain boundaries. Interestingly, the chemistry was typically significantly different on each side of the boundaries. In the vicinity of grain boundaries, zones that appear to be entirely depleted in alloying elements are usually found. The regions appear only on one side of the boundary (see Figures 1-3) and typically extend for approximately 5-10 nm. Within these depletion zones, even the otherwise omnipresent $\mathrm{Sn}$ can be absent.

\section{Fe distribution}

The grain-to-grain variation is particularly pronounced for Fe. Some analyses contain very little Fe, but at least some minor concentrations are always measured. As exemplified in Figure 1, the distribution is typically not homogeneous. Instead, small clusters of $0.5-10$ nanometer sizes are seen to be aligned along planes within the Zr matrix (Figure 2). The distance between these planes is typically $10 \mathrm{~nm}$. The Fe concentrations within these clusters do not indicate fully developed precipitates of a Fe-rich phase, as the measured concentrations rarely exceed 5 at.\%.

As has previously been observed in APT studies of unirradiated Zr alloys [9,12], significant amounts of $\mathrm{Fe}$ are also found in some, but not all, metal grain boundaries. In some analyses, ring-shaped features of Fe were observed (Figure 3). No such features have been encountered in our studies of unirradiated Zircaloy-2. This is an indication that the rings arise from segregation of Fe to the edge of dislocation loops, most likely <c>-component vacancy loops. The diameters of the rings observed in this study are typically $20-50 \mathrm{~nm}$, which is slightly smaller than reported $<c>-$-loop sizes from TEM studies $[2,8]$. However, it should be noted that the limited volumes of APT analyses precludes detection of large loops in their entirety.

\section{Cr distribution}

Similar to $\mathrm{Fe}, \mathrm{Cr}$ exhibits a strong grain-to-grain variation where some regions are entirely depleted whereas others have a high concentration. Unlike the distribution of $\mathrm{Fe}$, which is found in every analysis, some regions contain virtually no $\mathrm{Cr}$ at all. $\mathrm{Cr}$ is almost exclusively found in nano-sized precipitates and clusters aligned along parallel planes within certain zones of the material (see Figure 2 and 3). The local concentration of $\mathrm{Cr}$ within the particles can be as high as 25 at.\%. A concentration profile across the interface between a Cr-rich particle and the surrounding Zr matrix is presented in Figure 4.

The number density and the composition of the Fe- and Cr-rich clusters vary from analysis to analysis. The highest number density was found in the analysis that is shown in Figure 2. An estiblished cluster search algorithm [20] was used to determine the maximum density of clusters in this region, using the parameters $d_{\max }=0.7 \mathrm{~nm}$ and $N_{\min }=10$. The resulting number density was calculated to be $(8 \pm 2) \times 10^{23} \mathrm{~m}^{-3}$. This is approximately a factor of 10 higher than 
the expected number densities of <a>-type dislocation loops after a similar neutron irradiation dose. The build-up of layers of particles resembles the arrangement of <a>-loops seen with TEM [2, 21-24] and it is therefore possible but not certain - that there is some correlation between the clustering and such defects. In particular there is agreement between the size and number densities of clusters and the small prismatic loops that were observed in Zircaloy-2 by Idrees [24]. The clusters are arranged in parallel planes, similar to the "corduroy"-like contrast of aligned <a>-loops that has been observed in TEM studies [2]. This could indicate that $\mathrm{Fe}$ and $\mathrm{Cr}$ clusters nucleate along the dislocation line or within the strain field of such defects. No grain boundary segregation or ring-shaped features of Cr was observed in any of the analyses in this study.

\section{Sn distribution}

In unirradiated material, Sn has a uniform matrix distribution and is believed to be substitutionally dissolved in $\alpha$-Zr. All analyses in this study have overall $\mathrm{Sn}$ contents close to the nominal composition of the material. As can be seen in Figure 1 and 2, some grain-to-grain variation in the Sn distribution occurs. Interestingly, in regions where significant $\mathrm{Fe}$ and $\mathrm{Cr}$ clustering is observed, $\mathrm{Sn}$ appears to be homogeneously distributed in the matrix with only weak signs of clustering. Conversely, some Fe- and Cr-lean regions exhibit Sn clustering of a few nanometer sizes, implying that they may be associated with <a>-loops. However, unlike $\mathrm{Cr}$, significant amounts of Sn are also found dissolved in the matrix surrounding the clusters.

As is the case for Fe, $\mathrm{Sn}$ is also found in the ring-shaped features that are understood to be $<c>$-component loops (see Figure 6). However, they do not appear to segregate simultaneously, as only one of either Fe or $\mathrm{Sn}$ is observed in any given loop.

\section{Ni distribution}

Little Ni is found in the analyzed samples. Some small amounts are sometimes found along with $\mathrm{Fe}$ and $\mathrm{Cr}$ in clusters aligned on parallel planes. In one of the analyzed samples (see Figure 2), a high concentration of $\mathrm{Ni}$ is found in a $50 \mathrm{~nm}$ planar region, in which $\mathrm{Fe}, \mathrm{Cr}$ and $\mathrm{Si}$ are also enriched. From our studies of unirradiated Zircaloy-2, we know that Ni-type precipitates typically contain significant amounts of Si. This is an indication that the feature in question is the remains of a prior $\mathrm{Zr}_{2}(\mathrm{Fe}, \mathrm{Ni})$-type precipitate, that has been dissolved by the radiation. No indications of grain boundary or $<$ c $>$-dislocation loop segregation of Ni were observed in the analyses.

\section{Hydrogen distribution}

All analyses contain large amounts of hydrogen, with concentrations varying between 20 and 66 at.\%. This is an order of magnitude more than the sample average (660 wppm) and reflects the tendency of hydrogen to form a hydride rim close to the outer cladding wall. Most of the hydride rim forms during cooldown from the operating temperature to room temperature. The spatial 
distribution is typically homogenous throughout each analysis, which suggests that each analysis runs through a single hydride phase, out of the different hydride phases that are present close to the metal-oxide interface. No elevated hydrogen concentrations are measured in or in the vicinity of defects such as $<$ a $>$ - or $<$ c $>$-loops or around grain boundaries.

\section{Oxygen ingress}

No oxygen was found in the vicinity of the defect structures of clusters and loops. One analysis was obtained across the interface between the sub-oxide $\mathrm{ZrO}$ phase and the metal underneath. The oxygen concentration profile across the phase boundary is presented in Figure 7. The oxygen concentration drops rapidly from 50 at.\% in the sub-oxide to a few atomic percent and reaches its base level of less than 1 at.\% about $50 \mathrm{~nm}$ into the $\mathrm{Zr}$ metal. Despite the proximity of all analyses to the oxide scale, very low overall 0 concentrations are measured in all analyses in the metal. No alloying element appears to be rejected by the sub-oxide front.

\section{Discussion}

\section{Alloying element distribution}

As is expected, the distribution of alloying elements in the cladding is significantly altered after prolonged in-reactor exposure. No SPPs of the sizes that are observed in the fresh material were encountered in any of the analyses due to the small total analyzed volume. We know from TEM of the same cladding tube that SPPs still exist in the material [18], but none were detected in our analyses. Instead precipitation of small secondary particles occurs in large numbers in the matrix. Due to the low solubility of Fe and $\mathrm{Cr}$ in the $\mathrm{Zr}$ matrix, a driving force for reprecipitation counteracts a randomized distribution induced by the collision cascades. The reprecipitation is significantly more pronounced for $\mathrm{Cr}$ than $\mathrm{Fe}$. $\mathrm{Fe}$ is found both in solid solution and in clusters, whereas $\mathrm{Cr}$ is found almost exclusively in clusters and precipitates. This is somewhat surprising as $\mathrm{Cr}$ is believed to diffuse slower than $\mathrm{Fe}$ and $\mathrm{Ni}$ [25]. This indicates that the number density of nucleation sites is very high and diffusion distances therefore so short that kinetics is not a limiting factor. Fe appears to have some non-negligible solubility in the Zr matrix, or alternatively be affected by the radiation to a larger extent than $\mathrm{Cr}$, as its kinetics for precipitation should be faster.

Alignment of evenly distributed small precipitates in the basal plane in Zircaloy2 has been reported previously by Griffiths [2]. It was inferred that the distance between the planes is not related to elastic interaction between adjacent particles, as such structures are not found in unirradiated heat-treated material. The segregation layers in this study also bears a striking resemblance to the corduroy-like build-up of dislocation loops around precipitates in the TEM micrographs that are presented by Valizadeh et al. [18].

Recent ab-initio calculations by Christensen et al. showed that Fe atoms, to a greater extent than $\mathrm{Cr}, \mathrm{Ni}$ and $\mathrm{Sn}$, attract vacancies in the $\mathrm{Zr}$ lattice [26]. It is possible that the apparent high concentrations of dissolved Fe atoms throughout the matrix are rather Fe-vacancy pairs. Similarly, Christensen and co-workers' 
calculations suggest strong attractions between $\mathrm{Zr}$ self-interstitials and $\mathrm{Fe}, \mathrm{Cr}$ and $\mathrm{Ni}$, which would imply that they should segregate to both vacancy and interstitial type <a>-loops.

It is interesting to note the large differences in chemistry and precipitation across grain boundaries. Large numbers of clusters accumulate on one side of the boundary, whereas a depletion zone exists on the other. Similar results have recently been published from in situ irradiation TEM studies [24], although the depletion zone was there reported to be wider than what is observed here. This may be an effect of the strong anisotropy of diffusion in $\alpha-Z r$, where for instance the activation energy of diffusion for self-interstitials is almost a factor of 3 higher in the <a>-directions than in the $<$ c $>$-direction [27]. As $\mathrm{Fe}, \mathrm{Ni}$ and $\mathrm{Cr}$ exhibit mobilities that are associated with interstitial diffusion [28], it is reasonable to assume that like self-interstitials these alloying elements move preferentially in the basal plane. Extensive data on the large differences in the build-up of radiation-induced defects within and between grains have also been obtained from transmission electron microscopy studies [29].

$\mathrm{The}_{\mathrm{Zr}_{2}}(\mathrm{Fe}, \mathrm{Ni})$ particles are larger than the $\mathrm{Zr}(\mathrm{Fe}, \mathrm{Cr})_{2}$ particles, and have a lower number density. Due to the very limited volumes that are included in an APT analysis, and the low $\mathrm{Ni}$ content of the material, the probability of encountering a region close to a prior $\mathrm{Zr}_{2}(\mathrm{Fe}, \mathrm{Ni}) \mathrm{SPP}$ is palpably slim. As expected, little $\mathrm{Ni}$ is found in the analyses with one exception. A majority of the $\mathrm{Ni}$ appears to remain in SPPs even after long-term exposure. This is in good agreement with the findings of Valizadeh et al. [18], who examined the same rod and found that crystalline $\mathrm{Zr}_{2}(\mathrm{Fe}, \mathrm{Ni})$ particles are still present after 9 annual reactor cycles. Even though the Ni content of Zr-2 is very low, it is known to have a major impact on hydrogen pickup, specifically on the accelerating instantaneous pickup fraction at high burnup.

\section{Defect structures}

In most cases APT analysis does not give explicit crystallographic information. This makes it difficult to unequivocally identify the nature of the defects that are observed in this study. The distinct segregation of $\mathrm{Fe}$ and $\mathrm{Cr}$ to clusters or precipitates in parallel planes has a number density that correlates with the size and density of prismatic loops seen by Idrees [24] and it is possible that they are nucleated on, or in the strain field of, such defects. However, unlike the ringshaped segregation around vacancy $<\mathrm{c}>$-component loops, the $\mathrm{Fe}$ and $\mathrm{Cr}$ nanoclusters typically have a shape close to spherical geometry. $<$ a $>$-loops can be of both vacancy and interstitial type, but the segregation to these clusters does never appear as rings. This may be due to the very small size of the dislocation loop, or an indication that the segregation occurs to the strain field around the loop rather than to the dislocation line. As can be seen in Figure 8, Cr clusters appear to have nucleated on the loop, but not along the dislocation line. Idrees compared the <a->-loop density in Zircaloy-2 with pure $\mathrm{Zr}$, and concluded that alloying elements play an important role in their nucleation [24]. APT analysis allows for more specific investigation of the nature of the loop segregation. $\mathrm{Sn}, \mathrm{Fe}$ and $\mathrm{Cr}-$ not $\mathrm{Ni}$-would appear to be the most important 
elements for <a>-loop stabilization if the assumption that the clusters are associated with these defects is correct.

The ring-shaped segregation features in the structure are interpreted to be $<\mathrm{c}>$ component loops, as the ring-shaped segregation of Fe or Sn indicates that they have a vacancy character. However, the diameters of the rings observed in this study are somewhat smaller than what is typically seen for $<$ c $>$-loops elsewhere $[2,8,18]$. The dislocation loop in Figure 8 is located in the same plane as the layers of $\mathrm{Cr}$ and Fe-rich particles (see Figure 10). There are strong indications that these layers are located on basal planes, as such segregation structures have been reported previously $[2,18]$. If this is true, the Burgers vector of the dislocation loop in Figure 10 lies in the $<0002>$ direction, and we can thus make the reasonable assumption that it is a $<\mathrm{c}>$-loop.

The local chemistry where the loop is formed appears to determine the segregating species. This implies that the defects exist continuously and reasonably homogenously throughout the grains, and the proximity to a prior SPP determines their chemistry. The rings are predominantly observed for $\mathrm{Fe}$ and in some cases also for Sn. It can therefore be assumed that these two elements play a role in the evolution of $<$ c $>$-loops. Some analyses contain no $\mathrm{Cr}$ or $\mathrm{Ni}$ and very little $\mathrm{Fe}$. In such regions, $\mathrm{Sn}$ is observed to segregate to various defects. In the initial stages of the cladding lifetime, Sn could play a more important role as it is homogenously distributed in the matrix, whereas Fe and Cr still remain in SPPs. However, the gradual dissolution of particles forces more and more $\mathrm{Fe}$ and $\mathrm{Cr}$ into the metal matrix and the impact of these elements on the $<$ c $>$-loop evolution may therefore increase with fluence, with consequences for irradiation growth during the later stages of the cladding lifetime. The role of $\mathrm{Ni}$ in this scenario is not clear, since we observed too few $\mathrm{Ni}$ atoms to draw any conclusions.

\section{Hydrogen ingress}

Hydrogen quantification with APT is notoriously difficult, as it is not possible to separate the corrosion products from adsorbed $\mathrm{H}_{2}$ gas from the vacuum chamber [30]. However, the hydrogen concentrations measured in this study are so high that one may confidently assume that the vast majority can be attributed to actual hydride phases in the material. As the tips were very resistant to fracture during analysis, the experimental conditions could be optimized in order to reduce gas adsorption onto the specimen [30].

As at least 20 at.\% hydrogen, and in some cases up to $66 \%$, is measured, it is safe to assume that the analyses run through various hydride phases. This is expected, as the terminal hydrogen solubility (which is approximately 200 wppm at $673 \mathrm{~K}\left(400^{\circ} \mathrm{C}\right)$ [31]) is exceeded in the material already during reactor operation temperatures. Hydrides are expected to precipitate close to the oxide, as this is the coolest part of the tube. Therefore, it is feasible that the hydride phases that are present in the material have formed already during operation. Solubility at room temperature is very low, and significant precipitation of hydrides is expected to occur throughout the tube as the temperature decreases 
after shutdown of the reactor. Although such a high hydrogen content was recorded that the analyses must have passed through hydride phases, we still observe features that most likely have formed in $\mathrm{Zr}$ metal. This suggests that the hydride inherits the microstructural features of the metal upon precipitation. No evidence for hydrogen interaction with loops and defects could be found in this study, although the hydrogen mapping with APT is too inaccurate to draw any conclusions on the matter.

At the time when the analyzed cladding tube was removed from the reactor, a significant acceleration in the hydrogen pick-up kinetics had occurred [18]. The reason for this increase in pick-up rate is not yet very well understood, and is subject to intense study. Clearly, it is related to $\mathrm{Ni}$, since close to $\mathrm{Ni}$-free relatives in the same family of alloys, do not show such an accelerated hydrogen pickup. In a recent paper by Lindgren, it is proposed that hydrogen moves through the oxide in hydroxylated grain boundaries, and the availability of cathodic sites inside the oxide scale, where protons may be reduced to $\mathrm{H}_{2}$, ultimately determines the rate of hydrogen pick-up [32,33]. As all alloying elements in Zircaloy-2 are more noble than Zr itself, the SPPs are likely to be active cathodic sites in the oxide while they are still close to or in direct contact with the underlying metal. The dissolution of SPPs will reduce the availability of cathodic sites in the oxide where $\mathrm{H}_{2}$ can evolve, such that hydrogen is allowed to penetrate deeper into the oxide and will be absorbed by the metal. Calculations by Lindgren et al. indicate that in such a scenario, Ni should increase the hydrogen pickup fraction, while Fe should reduce it. The late-life acceleration of hydrogen pickup in Zircaloy-2, however, remains to be addressed in a mechanistic perspective.

\section{Oxygen ingress}

The existence of a sub-oxide layer of approximate composition $\mathrm{ZrO}$ has been reported on numerous occasions for Zr alloys [34-38] and was observed in these analyses as well. The fact that no rejection of alloying elements occurs ahead of the advancing oxide front suggests that the overall composition of alloying elements in the oxide is similar to that of the metal. The observed oxygen gradient suggests that the sub-oxide layer is no thicker than some $50 \mathrm{~nm}$.

In autoclave-tested materials, an oxygen saturated metal layer containing approximately 30 at.\% 0 is typically present under the sub-oxide scale [37,39]. It is interesting to note that this is not found in the analysis of the interface region in this study. A comprehensive mathematical treatment of the expected oxygen gradient from the oxide front and into the metal has been made by Béranger and Lacombe [40]. In this model, the oxygen gradient depends chiefly on the oxygen diffusivity in the metal. In the light of these calculations, the abrupt drop in oxygen concentration under the sub-oxide could therefore be interpreted as a result of an increase in the oxygen diffusivity, which could be caused by irradiation and/or an increasing hydrogen concentration. Due to the fast diffusion kinetics, oxygen would have sufficient mobility to distribute in the $\mathrm{Zr}$ bulk, as opposed to forming extensive gradients under the metal-oxide interface. The diffusion profile is also dependent on the oxidation rate, i. e. the velocity of 
the moving oxide front. The acceleration of the oxide growth may cause an instantaneous oxidation rate in excess of the diffusion rate of oxygen in the metal, thus not allowing for significant gradients in the metal underneath. This explanation appears less likely for the investigated sample, since the in-reactor oxidation rate was relatively low, also late in life.

\section{Conclusions}

An atom probe tomography study has for the first time been conducted on irradiated Zircaloy-2, that has been subjected to 9 annual cycles of BWR exposure. The $\mathrm{Zr}$ matrix region close to the metal-oxide interface was investigated with the view to determine how the alloying elements are redistributed after prolonged neutron irradiation and SPP dissolution. The main conclusions that may be drawn are as follows:

1. Large portions of the metal contain a dense distribution of Fe and Cr-rich clusters and precipitates of approximately 1-5 nm sizes, nucleated on parallel planes in the structure. The size of the particles correlates well with what is expected for <a>-loops in Zircaloy-2, and it is possible that they precipitate at, or in the strain field of, such defects.

2. Fe appears to have a non-negligible solubility in the $\mathrm{Zr}$ matrix, whereas $\mathrm{Cr}$ was found exclusively in small clusters and precipitates. Sn is essentially homogenously distributed, but signs of defect segregation were sometimes observed.

3. Fe and $\mathrm{Sn}$ were observed to segregate to ring-shaped features in the metal, interpreted to be $<$ c $>$-component vacancy loops. These alloying elements can therefore be assumed to play a key role in the evolution of the $<$ c $>$-loops, and therefore also in the breakaway growth phenomenon that occurs in Zircaloy-2 after prolonged in-reactor exposure.

4. A large grain-to-grain variation in terms of alloying element distribution was observed. The chemistry varies significantly across grain boundaries, with some zones nearly devoid of any $\mathrm{Fe}, \mathrm{Cr}$ or $\mathrm{Ni}$, whereas large amounts are found in an adjacent grain. This is attributed to strongly anisotropic diffusion of alloying elements.

5. The existence of a sub-oxide phase that has been widely reported for autoclave-corroded material was observed also in the irradiated Zircaloy2. However, unlike autoclave-tested $\mathrm{Zr}$ alloys, the irradiated material did not appear to have extended oxygen gradients in the metal underneath the oxide front. Irradiation-induced increase in oxygen diffusivity in the metal could explain the lack of oxygen-saturated $\alpha$-Zr phase that is normally seen in autoclaved samples. 


\section{Acknowledgements}

The authors would like to thank Daniel Jädernäs at Studsvik Nuclear AB and the MUZIC-2 consortium for useful discussions about the manuscript. Financial support was provided by Westinghouse Electric Sweden AB, Sandvik Materials Technology AB, Vattenfall AB, the Electric Power Research Institute, Studsvik Nuclear AB and the Swedish Research Council.

\section{References}

[1] F. Onimus. J.L. Béchade, Radiation Effects in Zirconium Alloys. Comprehensive Nuclear Materials, Amsterdam: Elsevier, 4 (2012) 1-31.

[2] M. Griffiths, J. Nucl. Mat., 159 (1988) 190-218

[3] R.W. Gilbert, M. Griffiths, G.J.C. Carpenter, J. Nucl. Mat., 135 (1985) 265-268

[4] W.J.S. Yang, R.P. Tucker, B. Cheng, R.B Adamson, J. Nucl. Mat. 138 (1986) 185195

[5] A.T. Motta, F. Lefebvre, C. Lemaignan, Zirconium in the Nuclear Industry: $9^{\text {th }}$ International Symposium, ASTM STP 1132, (1991), 718-739

[6] M. Griffiths, R.W. Gilbert, G.J.C. Carpenter, J. Nucl. Mat. 150 (1987) 53-66

[7] Y. de Carlan, C. Regnard, M. Griffiths, D. Gilbon, C. Lemaignan, Zirconium in the Nuclear Industry: 11 th International Symposium, ASTM STP 1295, (1996), 638-653

[8] P. Bossis, D. Pêcheur, K. Hanifi, J. Thomazet, M. Blat, Zirconium in the Nuclear Industry: $15^{\text {th }}$ International Symposium, ASTM STP 1467, (2006), 494-524

[9] D. Hudson, G.D.W. Smith, Scr. Mater. 61 (2009) 411-414

[10] D. Hudson, A. Cerezo, G.D.W. Smith, Ultramicroscopy 109 (2009) 667-671

[11] M. Thuvander, H.-O. Andrén, Ultramicroscopy 111 (2011) 711-714

[12] G. Sundell, M. Thuvander, H.-O. Andrén, Corr. Sci. 65 (2012) 10-12

[13] T. Sawabe, T. Sonoda, S. Kitajima, T. Kameyama, J. Nucl. Mat. 442 (2013) 168-174

[14] Y. Dong, A.T. Motta, E.A. Marquis, J. Nucl. Mat. 442 (2013) 270-281

[15] T. Andersson, T. Thorvaldsson, A. Wilson, A.M. Wardle, Improvements in Water Reactor Fuel Technology and Utilization, IAEA, Vienna, Austria, (1987), 435-449

[16] P. Tejland, M. Thuvander, H.-O. Andrén, S. Ciurea, T. Andersson, M. Dahlbäck, L. Hallstadius, Zirconium in the Nuclear Industry: $16^{\text {th }}$ International Symposium, ASTM STP 1529, (2011), 595-619

[17] P. Tejland, H.-O. Andrén, J. Nucl. Mat. 430 (2012) 64-71

[18] S. Valizadeh, G. Lederberger, S. Abolhassani, D. Jädernäs, M. Dahlbäck, E.V. Mader, G. Zhou, J. Wright, L. Hallstadius, Zirconium in the Nuclear Industry: $16^{\text {th }}$ International Symposium, ASTM STP 1529, (2011), 729-753

[19] D.J. Larson, D.T. Ford, A.K. Petford-Long, H. Liew, M.G. Blamire, A. Cerezo, G.D.W. Smith, Ultramicroscopy 79 (1999), 287-293.

[20] A. Cerezo, L. Davin, Surf. Interface Anal. 39 (2007), 184

[21] V.N. Shishov, Zirconium in the Nuclear Industry: $16^{\text {th }}$ International Symposium, ASTM STP 1529, (2011), 37-66

[22] V.N. Shishov, M.M. Peregud, A.V. Nikulina, P.V. Shebaldov, A.V. Tselischev, A.E. Novoselov, G.P. Kobylyansky, Z.E. Ostrovsky, V.K. Shamardin, Zirconium in the Nuclear Industry: $13^{\text {th }}$ International Symposium, ASTM STP 1423, (2002), 758-779 
[23] S.A. Averin, V.L. Panchenko, A.V. Kozlov, L.P. Sinelnikov, V.N. Shishov, A.V. Nikulina, Zirconium in the Nuclear Industry: $12^{\text {th }}$ International Symposium, ASTM STP 1354, (2000), 105-121

[24] Y. Idrees, PhD Thesis, Department of Mechanical and Materials Engineering, Queen's University, Canada (2013)

[25] G. M. Hood, J. Nucl. Mat. 159 (1988) 149-175

[26] M. Christensen, W. Wolf, C.M. Freeman, E. Wimmer, R.B. Adamson, L. Hallstadius, P.E. Cantonwine, E.V. Mader, J. Nucl. Mat. 445 (2014) 241-250

[27] F. Christien, A. Barbu, J. Nucl. Mater. 346 (2005) 272

[28] G.M. Hood, R.J. Schultz, Zirconium in the Nuclear Industry: $8^{\text {th }}$ International Symposium, ASTM STP 1023, (1989), 435-450

[29] M. Griffiths, R.A. Holt, J. Nucl. Mat. 225 (1995) 245-258

[30] G. Sundell, M. Thuvander, H.-O. Andrén, Ultramicroscopy 132 (2013) 285289

[31] C. Lemaignan and A.T. Motta, Chapter 7, "Zirconium Alloys in Nuclear Applications" in "Materials Science and Technology - A Comprehensive Treatment", Editors: R.W. Cahn, P. Haasen, E.J. Kramer, Volume 10B: "Nuclear Materials Part II", , Volume Editor B.T. Frost, (1994), [32] M. Lindgren, I. Panas, G. Sundell, L. Hallstadius M. Thuvander, H.-O. Andrén, Zirconium in the Nuclear Industry 17th International Symposium, ASTM STP (2013), Accepted

[33] M. Lindgren, I. Panas, RSC Adv. 3 (2013) 21613-21619

[34] H.-J. Beie, A. Mitwalsky, F. Garzarolli, H. Ruhmann, H.-J. Sell.

Zirconium in the Nuclear Industry 10th International Symposium, ASTM STP 1245 (1994) 615-643

[35] A. Yilmazbayhan, E. Breval, A.T. Motta, R.J. Comstock. J. Nucl. Mat. 349 (2006) 265.

[36] H. Anada, K. Takeda, Zirconium in the Nuclear Industry: 11th International Symposium, ASTM STP 1295 (1996) 35-54

[37] N. Ni, D. Hudson, J. Wei, P. Wang, S. Lozano-Perez, G.D.W. Smith, J.M. Sykes, S.S. Yardley, K.L. Moore, S. Lyon, R. Cottis, M. Preuss,

C.R.M. Grovenor, Acta Mater. 60 (2012) 7132-7149

[38] B. Wadman, H.-O. Andrén, , Zirconium in the Nuclear Industry: 9th International Symposium, ASTM STP 1132 (1991) 461-475

[39] P. Tejland, H.-O. Andrén, G. Sundell, M. Thuvander, B. Josefsson, L. Hallstadius, M. Ivermark, M. Dahlbäck, Zirconium in the Nuclear Industry: 17th International Symposium, Accepted

[40] G. Béranger, P. Lacombe, J. Nucl. Mat. 16 (1965) 190-207 


\section{Figures}
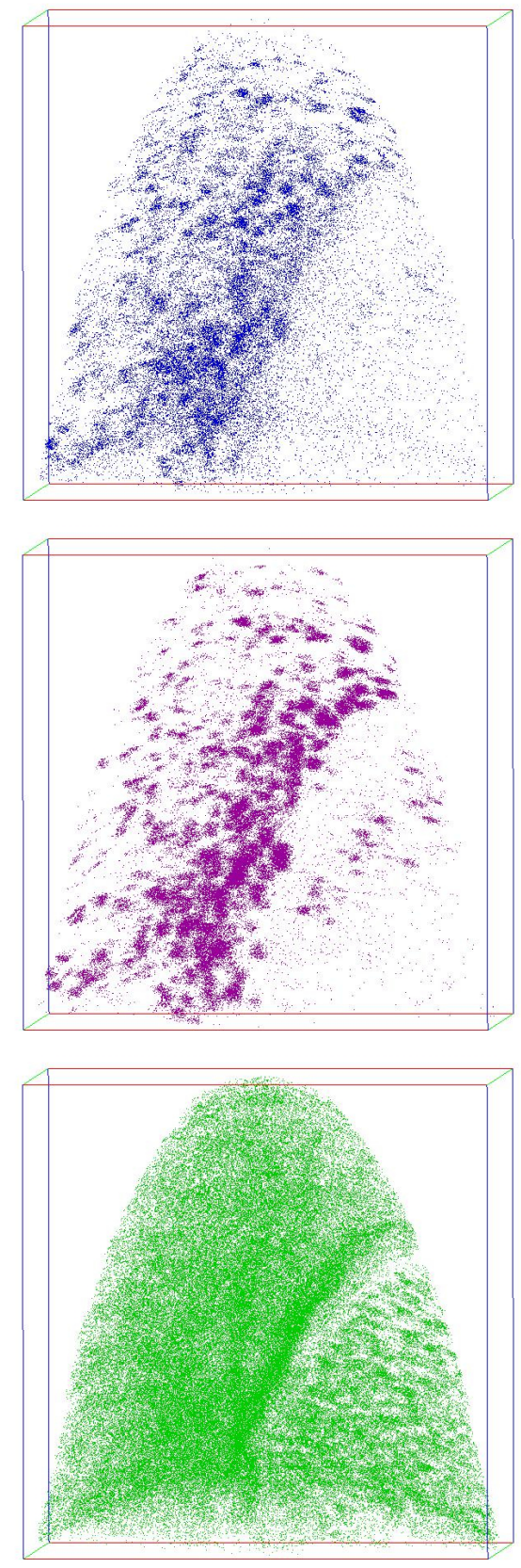

Figure 1: Distribution of Fe atoms (blue), Cr atoms (purple) and Sn atoms (green) in two adjacent grains in the Zr metal. Note that a high number of Fe and Cr clusters are present in the grain to the left, where $\mathrm{Sn}$ is distributed homogenously. To the right of the grain boundary, few clusters exist and Sn is instead seen to segregate to defects. The size of the box is $140 \times 140 \times 140 \mathrm{~nm}^{3}$. 

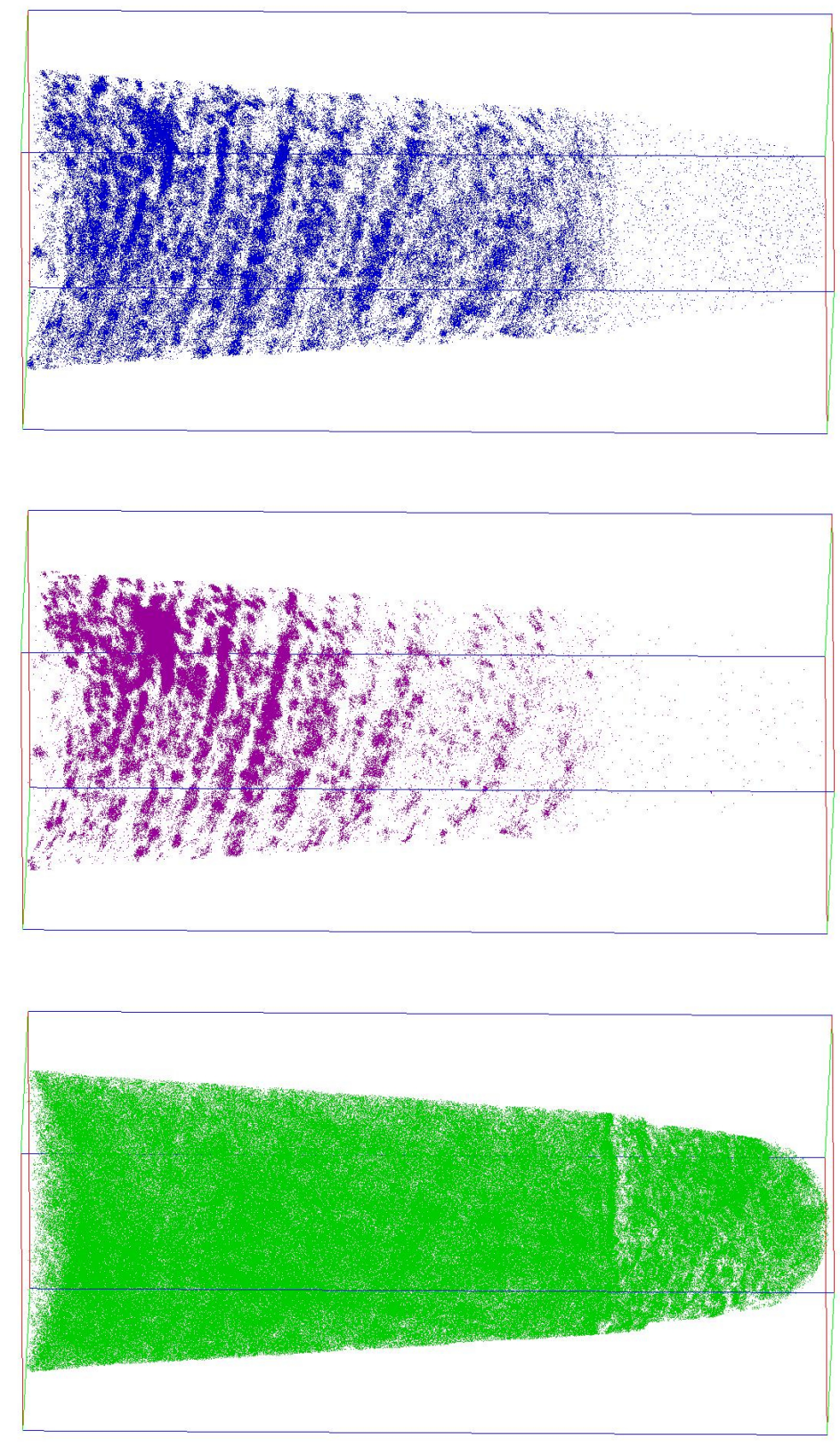

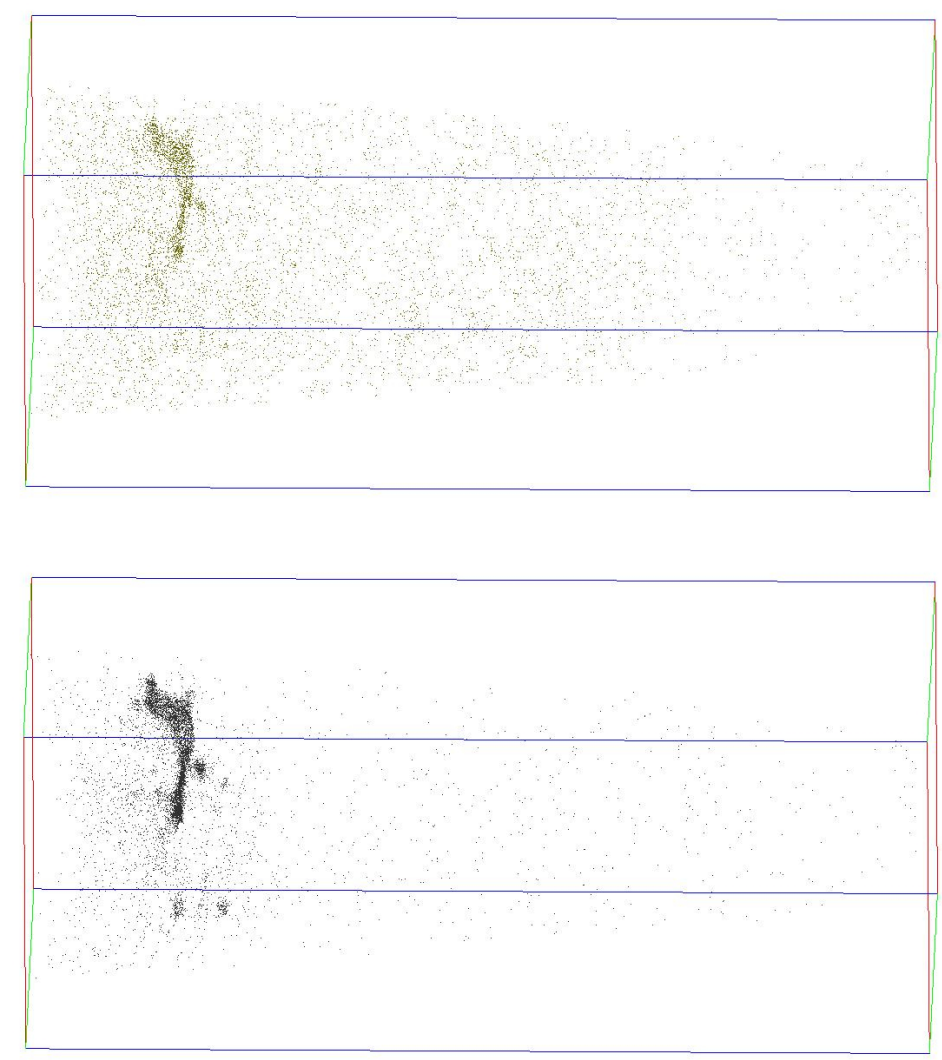

Figure 2: Distribution of alloying elements Fe (a), Cr (b), Sn (c), Ni (d) and Si (c) in a typical APT analysis. The size of the box is $360 \times 140 \times 140 \mathrm{~nm}^{3}$. Note the segregation structure, in which clusters are aligned in parallel planes for $\mathrm{Fe}, \mathrm{Cr}$ and Ni. To the upper left of the box is likely the remains of a prior $\mathrm{Zr}_{2}(\mathrm{Fe}, \mathrm{Ni}) \mathrm{SPP}$. The apparent change in plane angle along the axis of the analysis is an artifact of the reconstruction. 

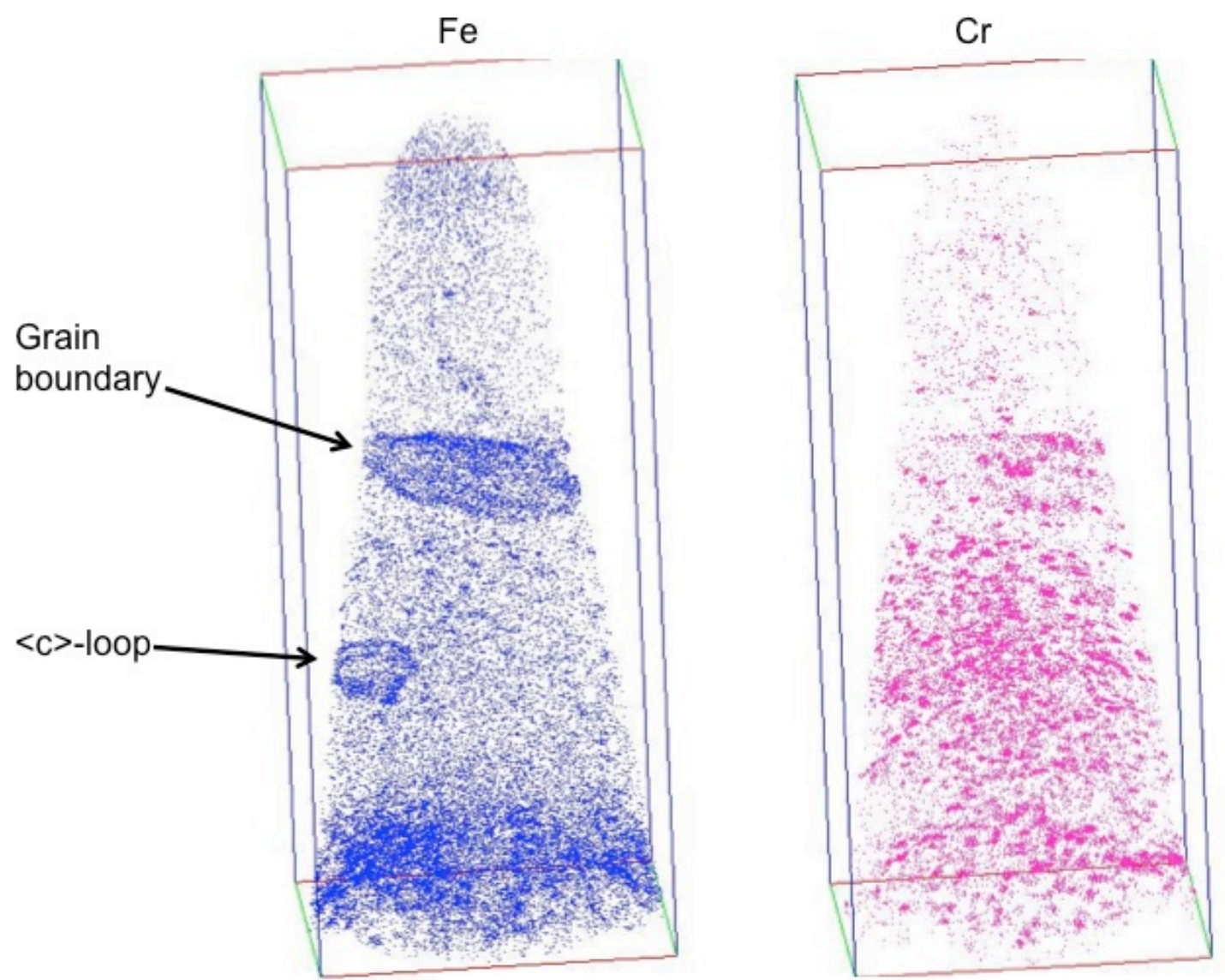

Figure 3: Distribution of Fe and $\mathrm{Cr}$ in an APT analysis. Fe (left) is seen to segregate to a grain boundary and an assumed $<\mathrm{c}>$-component loop, but not to clusters. $\mathrm{Cr}$ (right) is not residing in the grain boundary or the $<\mathrm{c}>$-loop but has formed a large number of nano-sized clusters. The size of the box is $400 \times 170 \times 170 \mathrm{~nm}^{3}$. 
(a)
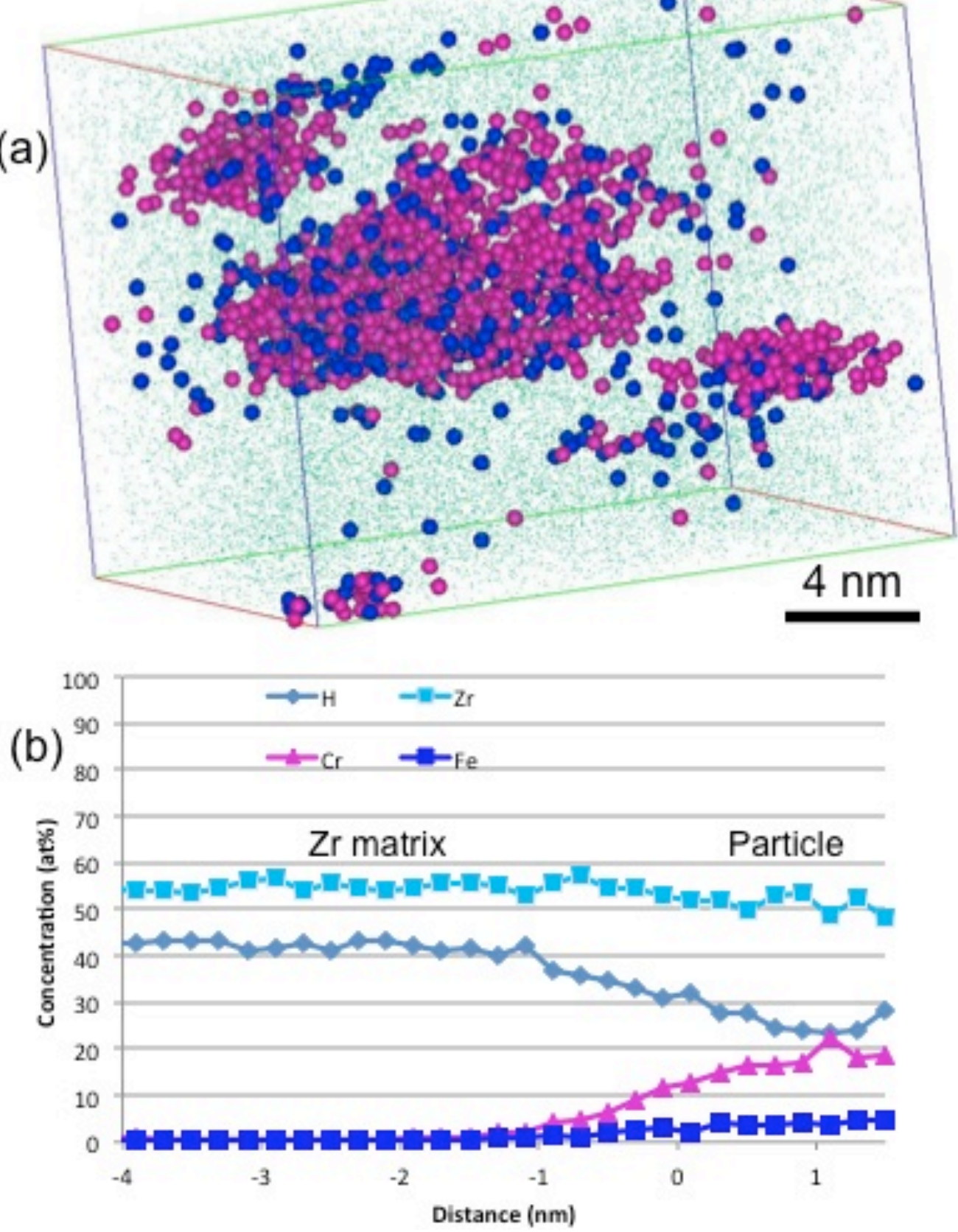

Figure 4: (a) displays three Cr particles in the Zr matrix. For clarity Cr (purple) and $\mathrm{Fe}$ (dark blue) atoms are enlarged compared to $\mathrm{Zr}$ atoms (turquoise). (b) shows a proximity histogram of the concentration profile from the Zr matrix into the large particle in the middle of (a). 
(a)

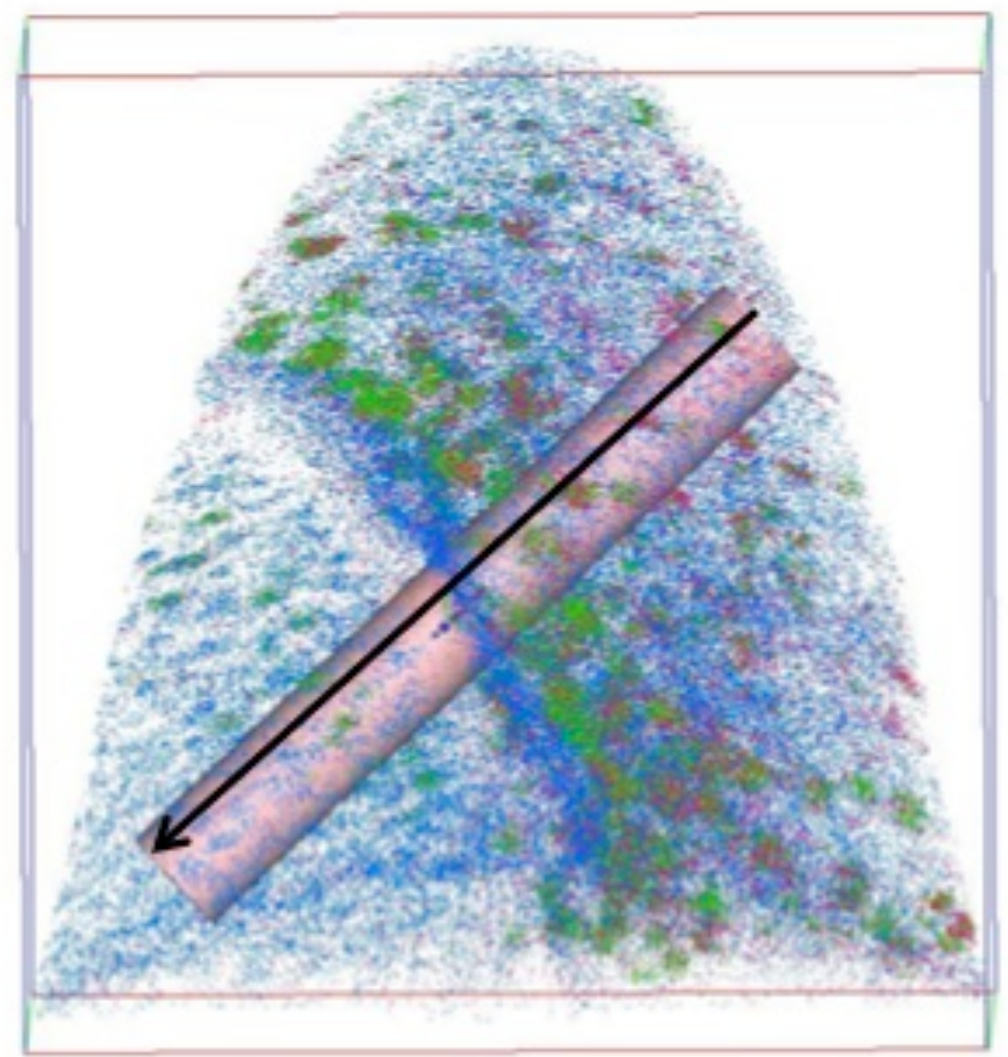

(b)

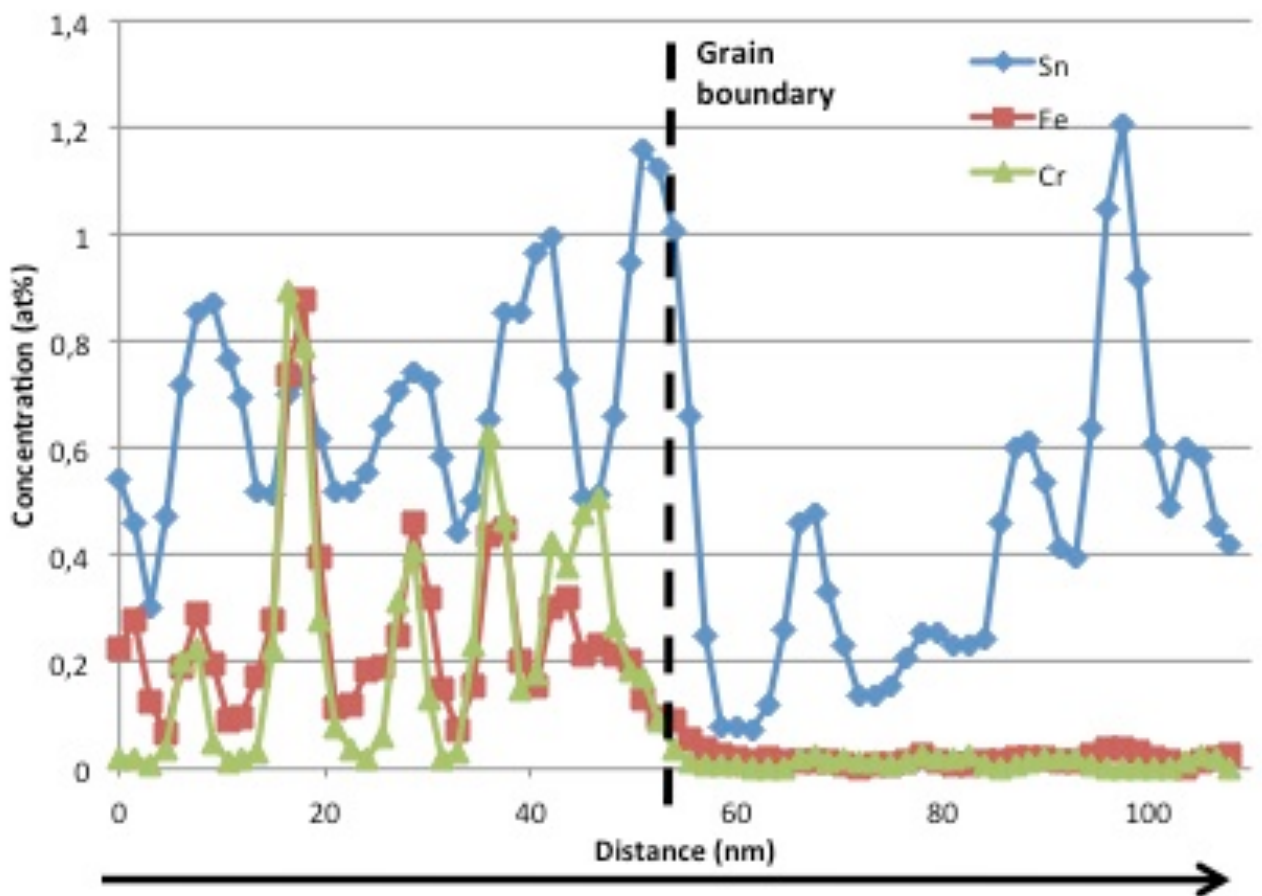

Figure 5: (a) displays the distribution of alloying elements across a grain boundary. Sn atoms are blue, $\mathrm{Cr}$ atoms green and Fe atoms red. The size of the box is $140 \times 140 \times 140 \mathrm{~nm}^{3}$. A concentration profile across the length of the tube in (a) for $\mathrm{Fe}, \mathrm{Cr}$ and $\mathrm{Sn}$ is displayed in (b). The arrow indicates the direction of the profile. 


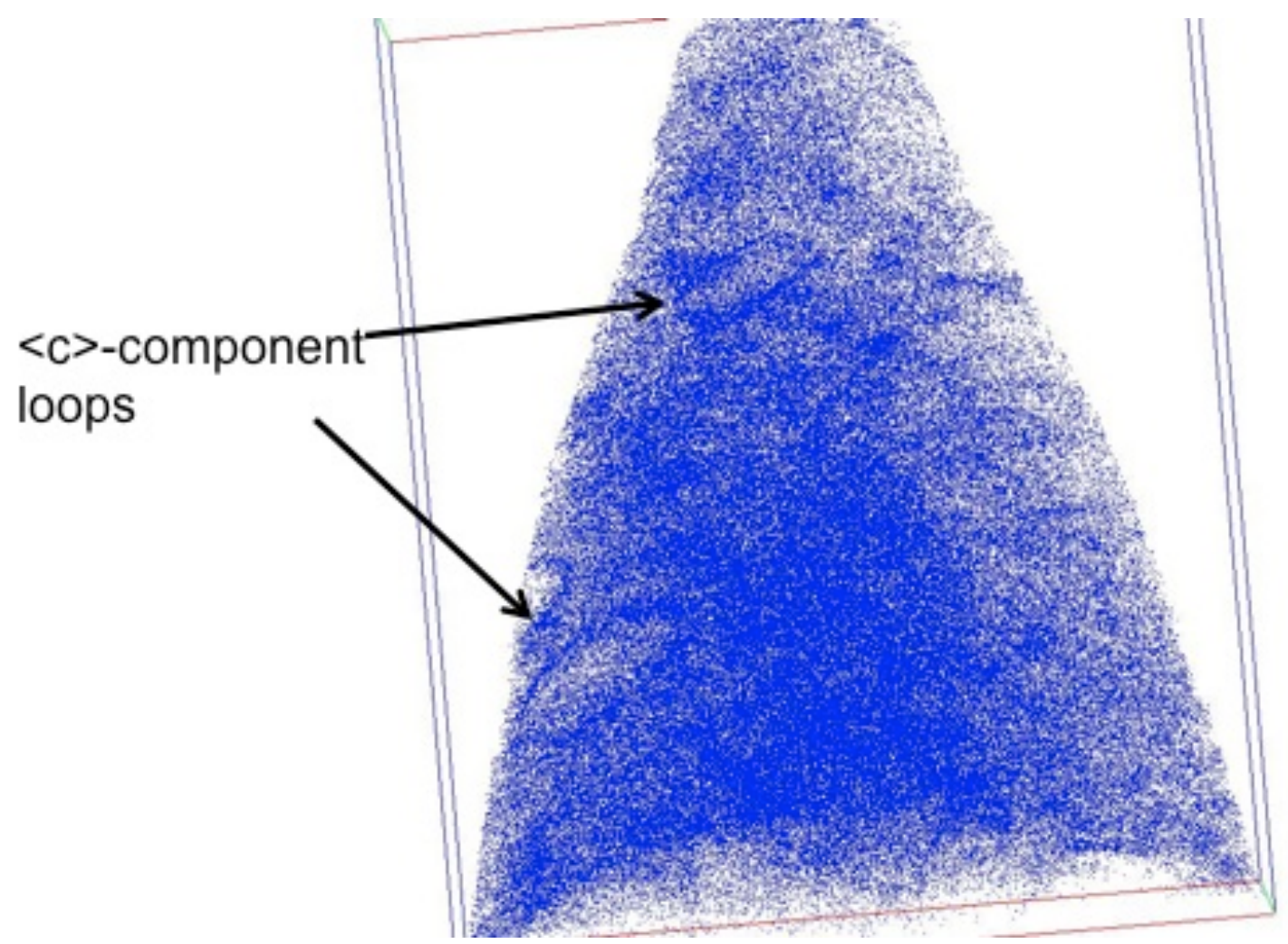

Figure 6: Segregation of Sn to assumed $<\mathrm{c}>$-component loops in the $\mathrm{Zr}$ metal. The size of the box is $140 \times 140 \times 180 \mathrm{~nm}^{3}$.

(a)
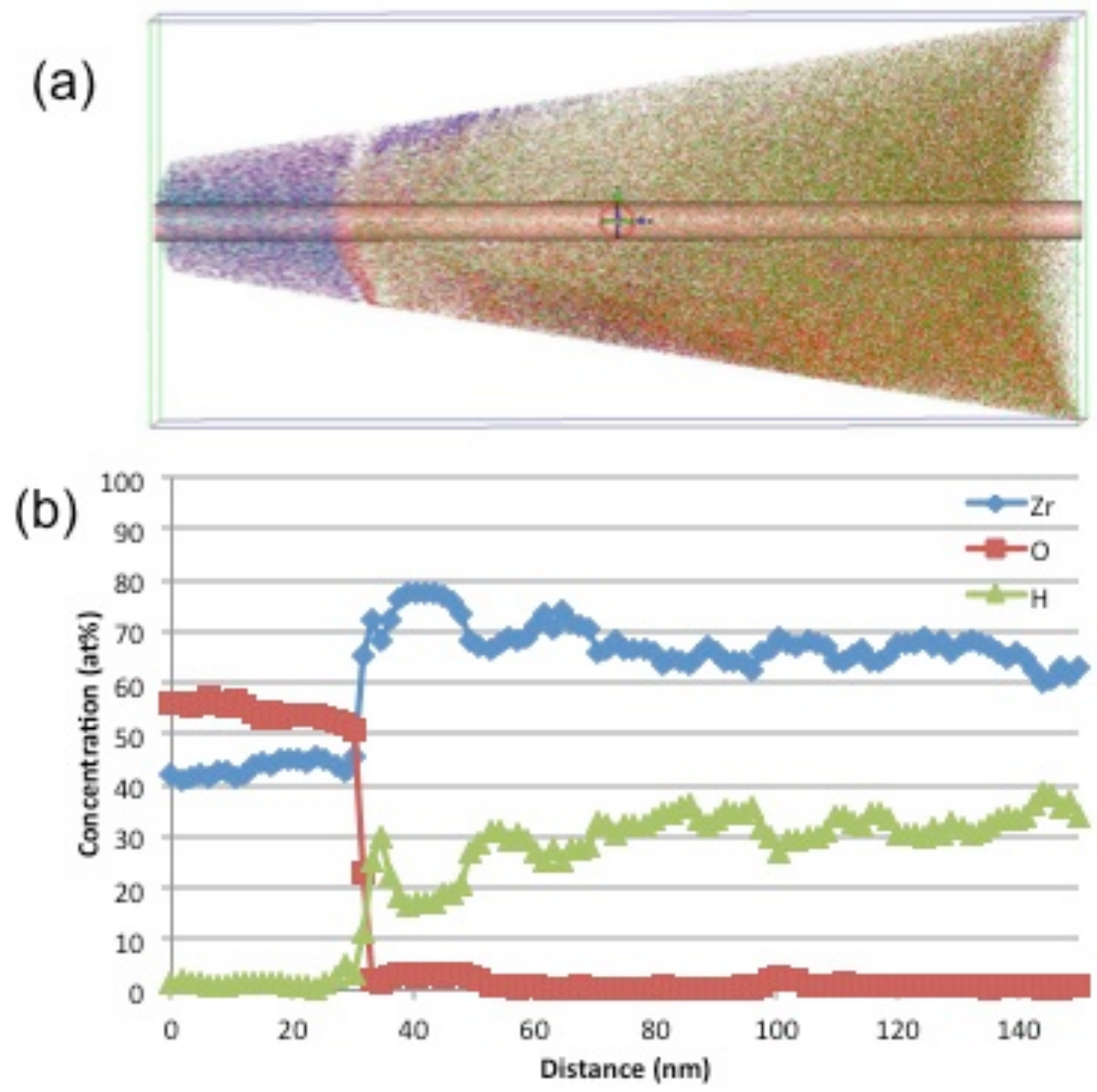
Figure 7: $\mathrm{O}, \mathrm{H}$ and $\mathrm{Zr}$ concentration profiles from the sub-oxide and into the $\mathrm{Zr}$ metal.

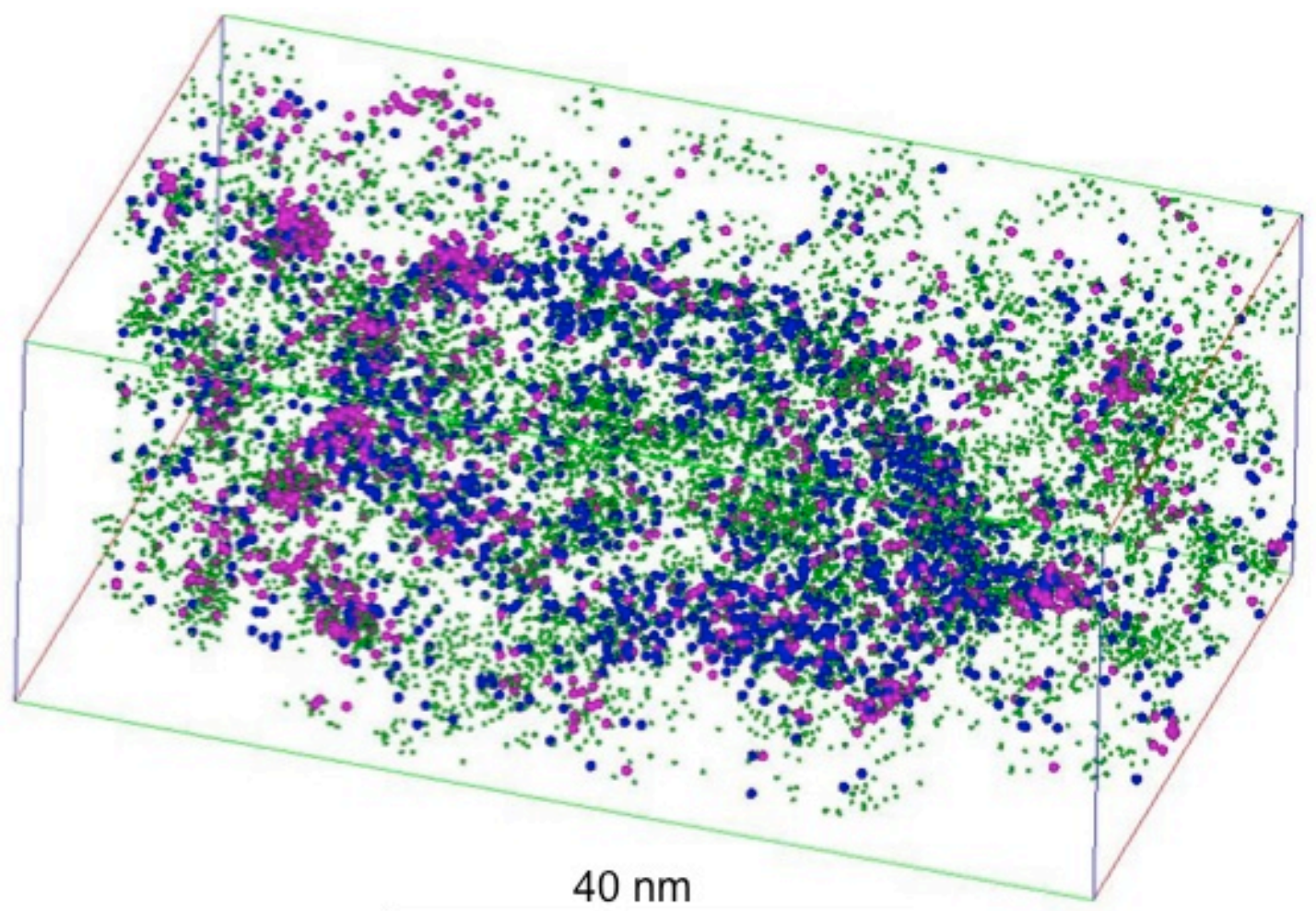

Figure 8: Segregation of alloying elements around a dislocation loop, interpreted to be of $<\mathrm{c}>$-component character. Fe atoms are blue, $\mathrm{Cr}$ atoms are purple and $\mathrm{Sn}$ atoms are green.

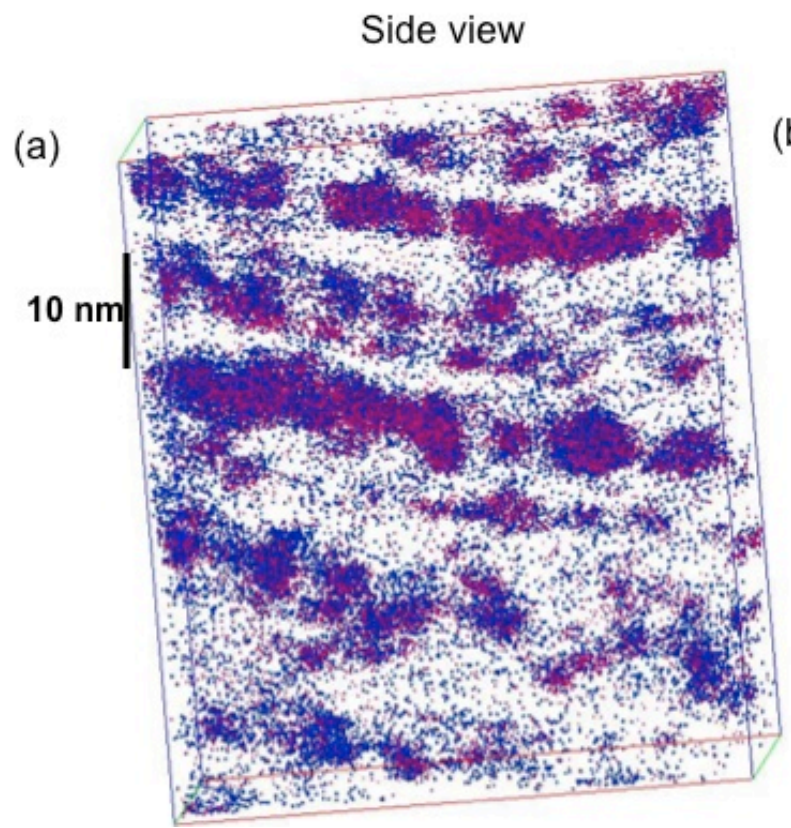

Top view of one layer

(b)

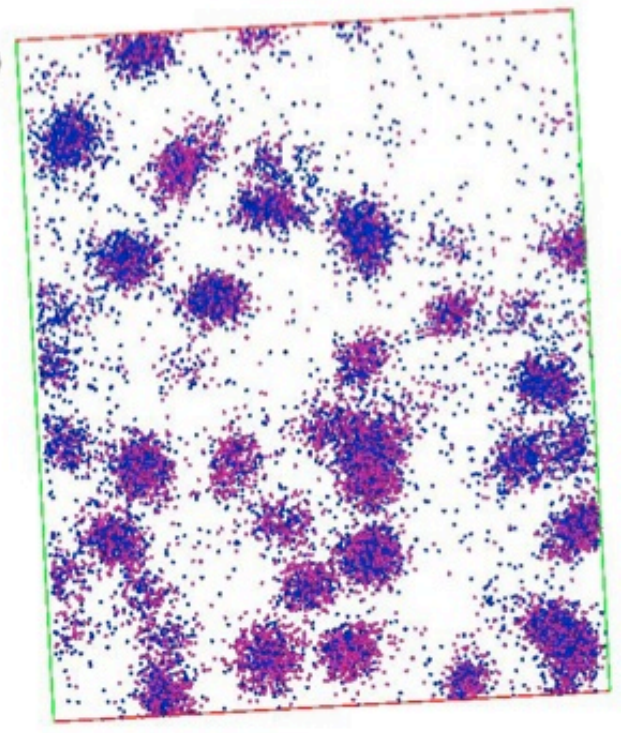

Figure 9: (a) shows a side view of the layered structure of the $\mathrm{Fe}$ (blue) and $\mathrm{Cr}$ (purple) particles in the structure. The distance between the planes is 
approximately $10 \mathrm{~nm}$. (b) shows a top view of a single layer.

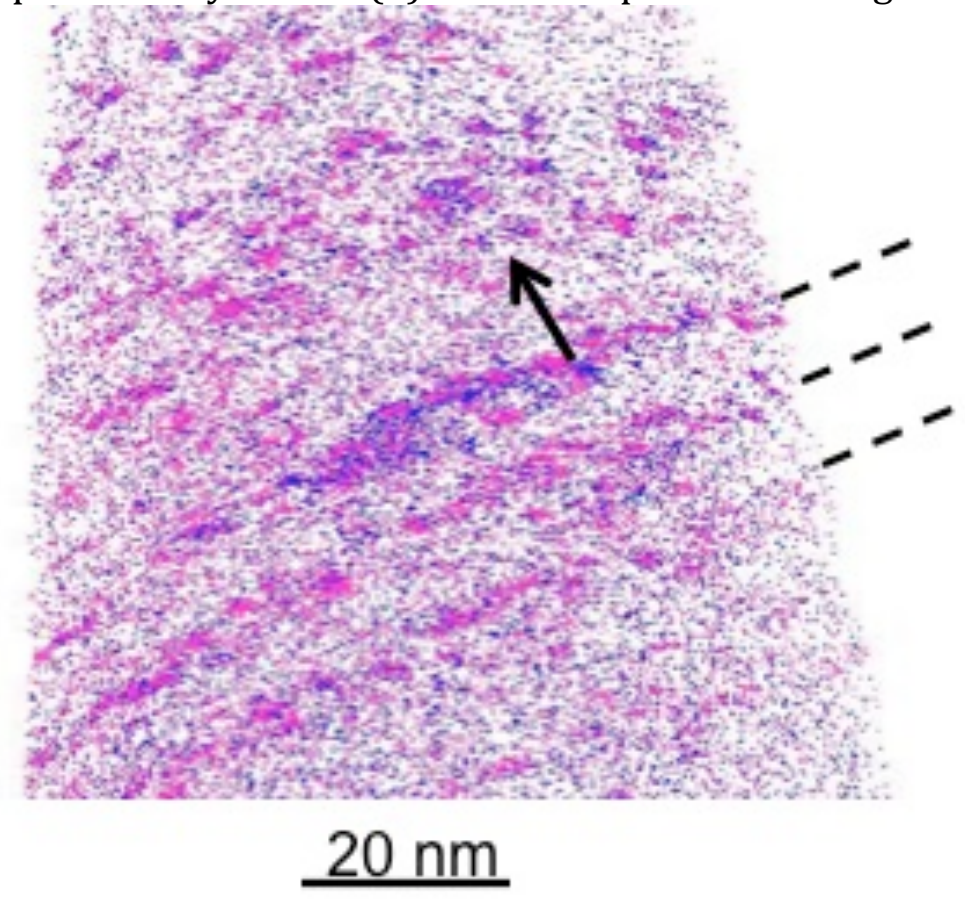

Figure 10: In-plane view of a Fe decorated dislocation loop. The direction of burgers vector is indicated by the arrow, and dashed lines indicate layers of $\mathrm{Cr}$ clusters that are assumed to be nucleated on basal planes. Fe atoms are blue and $\mathrm{Cr}$ atoms purple. 